\title{
Establecimiento e implementación de un protocolo simplificado de expansión y cultivo de Células Madre de Pulpa Dental Humana (DPSCh)
}

\author{
Establishment and implementation of a simplified protocol for \\ expansion and culture of Human Dental Pulp Stem Cells (DPSCh)
}

Estabelecimento e implementação de um protocolo simplificado para expansão e cultura de células-tronco da polpa dentária humana (DPSCh)

\author{
Alejandro Francia' (iD) 0000-0002-7942-9189 \\ Guillermo Grazioli (iD 0000-0001-9969-3780 \\ Lourdes Echarte ${ }^{3}$ (DD 0000-0001-6083-1621 \\ Álvaro Maglia ${ }^{4}$ (D) 0000-0002-1286-6720 \\ Cristina Touriñ 5 (DD 0000-0003-2681-2704 \\ Inés Alvarez ${ }^{6}$ (D) 0000-0001-5964-2903
}

DOI: $10.22592 / o d e 2021 n 37 e 207$

\section{Resumen}

Objetivos: Establecer e implementar un protocolo simplificado de extracción, aislamiento primario y cultivo de células madre derivadas de la pulpa dental humana (DPSCh). Analizar cuantitativamente y cualitativamente las células aisladas.

Metodología: 10 terceros molares sanos donados por pacientes que concurrieron a la Facultad de Odontología, Universidad de la República y otorgaron su consentimiento escrito fueron procesados antes de las 48 hs. Se realizó la fractura de la pieza para la obtención del tejido pulpar y se procesó por el método explante. Se analizó viabilidad celular y expresión de marcadores por citometría de flujo en pasajes 4 y 12 y se corroboró mediante inmunocitoquímica.

Resultados: Las células obtenidas presentaron una vitalidad mayor al $90 \%$ en todos los pasajes, observándose una morfología característica y expresión de marcadores de células madre mesenquimales CD90, C105, CD73, CD29 y 166 mediante citometría de flujo en ambos pasajes.

Conclusiones: Se logró establecer un protocolo de aislamiento y expansión celular, con alta tasa de éxito de una población de DPSCh.

Palabras clave: Células Madre Adultas, Pulpa Dental, Separación Celular, Citometría de Flujo, Células Madre Mesenquimatosas.

Cátedra de Fisiología general y bucodental, Facultad de Odontología Universidad de la República, Uruguay

Cátedra de Materiales Dentales, Facultad de Odontología Universidad de la República, Uruguay

Área Terapia Celular y Medicina Regenerativa (ATCMR), Departamento Básico de Medicina, Hospital de Clínicas, Facultad de Medicina, Universidad de la República, Uruguay

4 Cátedra de Histología y Embriología Bucodental, Facultad de Odontología, Universidad de la República, Uruguay

5 Área Terapia Celular y Medicina Regenerativa (ATCMR), Departamento Básico de Medicina, Hospital de Clínicas, Facultad de Medicina, Universidad de la República, Uruguay

6 Instituto Nacional de Donación y Trasplante (INDT), Ministerio de salud Pública- Hospital de Clínicas, Facultad de Medicina, Universidad de la República, Uruguay

Fecha de recibido: 7/7/2020 - Fecha de aceptado: 27/5/2021 


\section{Abstract}

Objectives: To establish and implement a simplified protocol for the extraction, primary isolation and culture of human dental pulp stem cells (DPSCh). Analyze the isolated cells quantitatively and qualitatively.

Methodology: 10 healthy third molars donated by patients who attended the Faculty of Dentistry, UdelaR and gave their written consent, were processed before 48 hours. The fracture of the piece was performed to obtain the pulp tissue and it was processed by the explant method. Cell viability and marker expression were analyzed by flow cytometry in passages 4 and 12 and confirmed by immunocytochemistry.

Results: The cells obtained showed a vitality greater than $90 \%$ in all the passages, observing a characteristic morphology and expression of mesenchymal stem cell markers CD90, C105, CD73, CD29 and 166 by flow cytometry in both passages.

Conclusions: It was possible to establish a cell isolation protocol, with a high success rate and safety to isolate DPSCh.

Key Words: Adult Stem Cells, Dental Pulp, Cell Separation, Flow Cytometry, Mesenchymal Stem Cells.

Keywords: Adult Stem Cells, Dental Pulp, Cell Separation, Flow Cytometry, Mesenchymal Stem Cells.

\section{Introducción}

Las células madre o estromales son células indiferenciadas presentes en el organismo en las etapas embrionarias, fetales y adultas. Estas células darán lugar tras la diferenciación a células específicas que constituyen los tejidos y órganos (1-3). Según su origen pueden clasificarse en: células madre embrionarias, células madre fetales, células madre adultas y células madre pluripo-

\section{Resumo}

Objetivos: Estabelecer e implementar um protocolo simplificado para a extração, isolamento primário e cultura de células-tronco da polpa dentária humana (DPSCh). Analise as células isoladas quantitativa e qualitativamente.

Metodologia: 10 terceiros molares saudáveis doados por pacientes que frequentaram a Faculdade de Odontologia UdelaR e deram consentimento por escrito foram processados antes de 48 horas. A fratura da peça foi realizada para obtenção do tecido pulpar e processada pelo método do explante. A viabilidade celular e a expressão do marcador foram analisadas por citometría de fluxo nas passagens 4 e 12 e confirmadas por inmunocitoquímica.

Resultados: As células obtidas apresentaram viabilidade superior a $90 \%$ em todas as passagens, observando uma morfologia característica e expressão dos marcadores de células-tronco mesenquimais CD90, C105, CD73, CD29 e 166 por citometría de fluxo em ambas as passagens.

Conclusóes: Foi possível estabelecer um protocolo de isolamento celular, com alta taxa de sucesso e segurança para isolar o DPSCh.

Palavras-chave: Células-Tronco Adultas, Polpa Dentária, Separação Celular, Citometría de Fluxo, Células-Tronco Mesenquimais.

tentes inducidas (iPSCs- induced pluripotent stem cells) ${ }^{(4)}$. Mientras que según su potencial de diferenciación se pueden clasificar en: totipotentes, pluripotentes, multipotentes, oligopotentes y unipotentes ${ }^{(4)}$.

Las características que identifican a las células estromales mesenquimales (MSC) son: adherencia al plástico en condiciones de cultivo estándar, capacidad de autorrenovación, potencia de dife- 
renciación a linajes óseo, condral y adiposo, y expresión de marcadores de superficie, tales como CD73, CD90 y CD105, además de la baja expresión de MHC-I y ser negativas para MHC-II, CD11b, CD14, CD34, CD45 y CD31 ${ }^{(5,6)}$.

El concepto de "stem" o "célula madre" de la población de células identificadas por estas características ha sido cuestionado ampliamente, aunque se reconoce que dentro de esta población existen una subpoblación minoritaria con propiedades de célula madre, por lo cual nos referiremos a las mismas como MSC ${ }^{(7,8)}$.

De este modo, las MSC se consideran candidatas prometedoras en el tratamiento de varias enfermedades debido a su facilidad de disponibilidad, capacidad de diferenciación y función inmunomoduladora ${ }^{(5,9,10)}$.

Se han identificado y descrito diferentes "nichos" de MSC adultas relacionadas con los órganos dentarios. Estas células, dependiendo de la zona en la cual se encuentren, adoptan diferentes denominaciones y se nombran por su sigla en inglés. Hasta la fecha se han identificado: células madre en la pulpa dentaria de las piezas permanentes (Dental Pulp Stem Cells - DPSCh), células madre de la pulpa dentaria de los dientes temporarios (Stem cells from Human Exfoliated Deciduous theeth - SHED), células madre del ligamento periodontal (Periodontal Ligament Stem Cells - PDLSC), células madre de la papila apical (Stem Cells from Apical Papilla - SCAP) y las células madre del folículo o saco peridentario (Dental Follicuar Stem Cells - DFSC) ${ }^{(1-15)}$.

Las DPSCh prometen ser una fuente de células madre aplicables en medicina regenerativa, en virtud que presentan su origen embrionario en la cresta neural, lo cual les brinda características particulares en relación con otras células madre mesenquimáticas ${ }^{(10,16-22)}$. En la actualidad se reconoce en estas células un alto potencial proliferativo y una gran plasticidad, lo que incentiva su aislamiento y uso clínico ${ }^{(13,23,24)}$. Existen diferentes estudios que prueban la capacidad de diferenciarse en diversos linajes celulares: fibroblástico, óseo, adiposo, condral, nervioso, muscular y pancreático ${ }^{(10,16-22)}$. Incluso se han observado diferencias en su comportamiento dependiendo del estado inflamatorio pulpar, característica que debe considerarse al momento de su uso ${ }^{(25,26)}$.

Si bien las DPSCh comenzaron a aislarse desde hace más de 20 años ${ }^{(12)}$, en Uruguay no se ha realizado este procedimiento. Debido a la gran variabilidad de protocolos existentes ${ }^{(27)}$, el desafío que implica dicho procedimiento y el escaso conocimiento en cultivos celulares por parte de los Odontólogos en nuestro país se pretendió adecuar los protocolos existentes a modo de establecer uno propio enfocado en las características de simplicidad, economía y efectividad para comenzar esta línea de investigación. Este estudio se desarrolló por primera vez en nuestro país mediante un protocolo simplificado de extracción de la pulpa dental, aislamiento primario, cultivo y expansión celular a partir de terceros molares sanos extraídos por indicación de ortodoncia. Nuestro objetivo fue analizar cualitativa y cuantitativamente las células obtenidas hasta pasaje 12 .

La hipótesis nula de este trabajo fue la no obtención de células madre de pulpa dental humana.

\section{Material y métodos}

\section{A) Selección, obtención y transporte de las muestras dentales}

Las muestras fueron obtenidas de pacientes de ambos sexos que concurrieron a los servicios asistenciales quirúrgicos de Facultad de Odontología - Universidad de la República, a realizarse extracción de terceros molares por motivos ortodóncicos y que otorgaron consentimiento informado para donar dichas piezas. Este estudio fue aceptado por el Comité de Ética de la Facultad de Odontología - UdelaR, Expediente: 091900-000143-13

Se incluyeron en este estudio terceros molares sanos, basando dicho diagnóstico en los criterios 
establecidos por el consenso de la Asociación Americana de Endodoncia ${ }^{(28)}$, sin importar la etapa de erupción en la que se encontraran o la etapa de desarrollo de su ápice, pero que hayan mantenido su integridad luego de la extracción. La edad del paciente fue de entre 16 y 30 años. Cualquier tipo de lesión cariosa, inflamación pulpar, infección relacionada o necesidad de fractura para la extracción determinaría la exclusión de la pieza para este estudio.

Se emplearon terceros molares sanos con extracción indicada por motivos ortodóncicos de 10 pacientes.

Todas las extracciones fueron coordinadas y se debió disponer durante la cirugía de un frasco refrigerado a $4^{\circ} \mathrm{C}$ con un preparado que llamamos medio de transporte, este consiste en una mezcla de el medio de cultivo comercial Alfa MEM (Capricorn Scientific, Alemania) suplementado con una alta carga antibiótica, Penicilina/Estreptomicina $100 \mathrm{U} / \mathrm{ml}$ (Capricorn Scientific, Alemania). Éste preparado tiene la finalidad de proporcionarle nutrientes a las células presentes en la pieza dentaria luego de extraída y permitir su supervivencia hasta ser procesadas en el laboratorio, mientras que la alta carga antibiótica inhibe el crecimiento bacteriano que puede haber sido acarreado durante la extracción desde la propia cavidad bucal.

Inmediatamente posterior a la extracción las piezas dentarias fueron colocadas en medio de transporte y conservadas a $4^{\circ} \mathrm{C}$. El transporte se realizó manteniendo la cadena de frío y el procesamiento dentro de las 48 horas inmediatas a su extracción en el Laboratorio preclínico de Ingeniería Tisular y Celular, del Instituto Nacional de Donación y Trasplante (LITYC - INDT).

Este procedimiento se realizó en dos etapas. Inicialmente el preprocesamiento de las piezas y luego la obtención del tejido pulpar propiamente dicha.

\section{B) Preprocesamiento de las piezas}

Para este procedimiento se confeccionó una cabina de acrílico donde se pueden introducir 4 manos y permite en un ambiente cerrado iniciar el procesamiento de las piezas. Esto permitió disminuir la contaminación tanto de la pieza como del ambiente.

Dentro de esta cabina acrílica, en primera instancia se removieron todos los restos de tejido periodontal presentes sobre las piezas dentarias con la ayuda de cureta de Gracey 14-15 (figura 1-a)., con la finalidad de evitar la contaminación de la muestra con otras células que no fueran las pretendidas. Luego se procedió al trazado de una línea de fractura, para ello se empleó una pieza de mano eléctrica y con disco de carborundum se trazó una ranura sobre el límite amelo-cementario, tendiendo hacia el cemento. En búsqueda de evitar sobrecalentamiento (lo cual sería negativo para las células de interés) se evitó desgastar esmalte durante el trazado de la ranura y se trabajó a 4 manos, manteniendo una irrigación constante con suero fisiológico. La ranura generada pretendió marcar una línea de fractura, bajo ningún concepto se expuso la cámara pulpar asegurando la esterilidad del tejido pulpar (imagen 1-b y c). Una vez realizado este procedimiento se retornó la pieza al medio de transporte para su traslado a la colecta propiamente dicha.

\section{C) Obtención del tejido pulpar}

Este proceso se realizó en cámara de flujo laminar FORMA 1300 A2, Modelo 1386 (Thermo Scientific, Waltham, Massachusetts, Estados Unidos). Previo al comienzo la cámara de flujo laminar fue descontaminada con alcohol $70 \%$ y esterilizada por luz UV durante 30 minutos. Para realizar el procedimiento se trabajó a 4 manos, durante el procedimiento tanto operador como asistente emplearon ropa estéril, sobre túnica, gorro, guantes, tapabocas, lentes y zapatones.

Para ingresar la pieza a la cámara de flujo laminar la misma fue descontaminada mediante una gasa embebida en alcohol 70\%. Una vez dentro, con el auxilio de dos fórceps no 101 se procedió a la fractura controlada de la pieza. Con uno de ellos 
se tomó la corona y con el otro la raíz, una vez seguros de la estabilidad de los fórceps se realizaron movimientos para la fractura combinando movimientos de rotación en sentido contrario de ambas partes y movimientos de quiebre. De esta manera se logró la separación de la corona anatómica de las raíces (Figura 1-d).

Una vez expuesto el tejido pulpar se procedió a su colecta con el auxilio de cucharas de dentina pequeñas y limas de endodoncia 15 y 25 . Todo el tejido obtenido se depositó sobre una placa Petri de vidrio. Las pulpas obtenidas fueron lavadas con buffer de fosfato salino (PBS- GIBCO, Dinamarca).

\section{D) Cultivo y expansión celular}

El cultivo se realizó mediante el método de explante, el cual consiste en obtener fragmentos (explantes) de tejido a partir del cual se pretende la migración de las células hacia el exterior, por este motivo, el tejido pulpar se cortó en bloques menores a $1 \mathrm{~mm}^{3}$ con el auxilio de dos mangos de bisturí con hojas número $15 \mathrm{C}$, creando de esa manera los explantes. Por otra parte, se tomó una placa de 6 pozos (Greiner CELLSTAR $^{\circledR}$, Sigma Aldrich, Missouri, Estados Unidos). Utilizando los mismos bisturíes se crearon 4 ranuras dibujando una cuadrícula en el piso de cada pozo, de este modo se ofrecen retenciones macro mecánicas para la fijación de los explantes. Se fijó un explante por cada intersección de las ranuras (imagen 1-e).

Una vez fijados los explantes se cargó cada pozo de la placa de cultivos gentilmente, colocando el líquido desde las paredes para no desplazar los explantes. Se colocaron $3 \mathrm{ml}$. de medio de cultivo clonogénico que fue preparado previamente con la siguiente composición: Alfa MEM (Capricorn Scientific, Alemania), Penicilina/Estreptomicina 1\% (Capricorn Scientific, Alemania), Suero Fetal Bovino 20\% (Capricorn Scientific, Alemania) y conservado a $4^{\circ} \mathrm{C}$, previo a su uso se colocó en baño a $37^{\circ} \mathrm{C}$ para elevar la temperatura y evitar estrés térmico al tejido pulpar. Finalmente, se colocó en incubadora (FORMA 311, Thermo Scientific, Waltham, Massachusetts, Estados Unidos) a $37^{\circ} \mathrm{C}$ y $5 \%$ de $\mathrm{CO}^{2}$ en ambiente de humedad.

Fig 1: Paso a paso en el protocolo de obtención y explante de DPSCh.
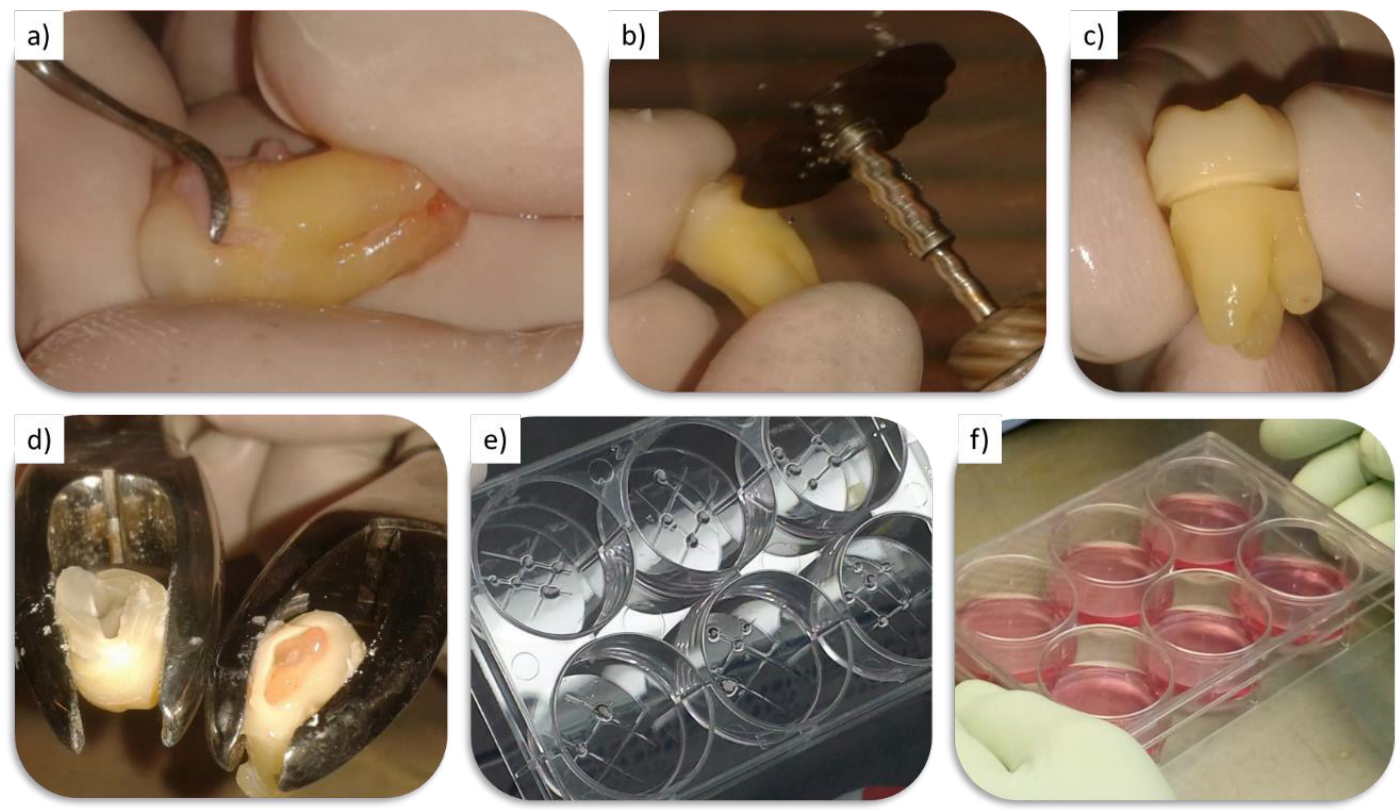

a) Limpieza de restos periodontales. b y c) desgaste para guía de fractura, sin exposición pulpar. d) fractura de la pieza utilizando fórceps. e) explantes colocados en las ranuras realizadas para su fijación mecánica. f) colocación de medio de cultivo. 
Se realizaron cambios de medio de cultivo cada 3 días. Para cada cambio se procedió a aspirar gentilmente el medio de cultivo antiguo utilizando una micropipeta de $1000 \mu$ l (Finnpipette F2, Thermo Scientific, EEUU), y luego se agregó nuevamente $3 \mathrm{ml}$ de medio de cultivo clonogénico.

El explante se mantuvo en su posición hasta conseguir la expansión celular deseada, $80 \%$ del pozo de la placa de cultivo cubierto de células. En esta instancia se procedió al primer pasaje y el explante retirado. La expansión celular se produjo en un periodo aproximado de 15 días (Fig. 1f).

Para cada pasaje se procedió inicialmente a retirar gentilmente el medio de cultivo antiguo, utilizando una micropipeta de $1000 \mu \mathrm{l}$ y el lavado del pocillo con las células adheridas mediante el agregado y retiro de $1 \mathrm{ml}$ de PBS. Luego, para poder desadherir las células se colocó en cada pozo $1 \mathrm{ml}$ de una preparación comercial de Tripsina/ EDTA (TrypLE ${ }^{\oplus}$, Thermo Scientific, Waltham, Massachusetts, Estados Unidos) y se llevó a la incubadora a $37^{\circ} \mathrm{C}$ por 5 minutos. Pasado este periodo se retira de la incubadora y se neutraliza la tripsina agregando en cada pozo $2 \mathrm{ml}$ de medio de cultivo clonogénico. De esta manera se obtiene en cada pozo una suspensión de células que luego se pasaron a una botella de cultivos t75 (Greiner, Sigma Aldrich, Missouri, Estados Unidos), los explantes fueron descartados.

Siguiendo este mismo criterio de expansión celular (cambio de medio cada 3 días hasta llegar a $80 \%$ de confluencia y luego realizar el pasaje) se realizaron 12 pasajes de manera consecutiva a $1 / 4$ de la suspensión celular en cada pasaje. El tiempo promedio para la confluencia en cada pasaje fue de aproximadamente 7 días.

\section{F) Evaluación de las células aisladas}

Viabilidad y Morfología celular por microscopía óptica: se utilizó microscopio invertido con contraste de fase (Nikon Ti-S, EEUU), con fluorescencia (Nikon, Ti-FL G-2A verde 510$560 \mathrm{~nm}$, EEUU) y cámara acoplada (Nikon, DS-Fi1c-U2, EEUU).
La viabilidad celular fue evaluada de forma cualitativa en los pasajes 1, 2, 4, 8 y 12 utilizando un indicador de viabilidad fluorescente (Fluoroquench ${ }^{\circledast}$ One Lambda, Thermo Fisher, EEUU) a un aumento de 5x. Para esto, una vez realizado el procedimiento de pasaje, se colocaron $40 \mu \mathrm{l}$ de suspensión celular en un pocillo de placa de Terasaki (Greiner, Sigma Aldrich, Missouri, Estados Unidos), a la cual se le agregaron $5 \mu \mathrm{l}$ de solución de Fluoroquench. Se la dejó reposar por 15 minutos a temperatura ambiente y luego se observó en microscopio invertido con fluorescencia, donde se observaron en verde las células viables, y en rojo las células muertas.

La morfología celular fue evaluada cualitativamente en los diferentes pasajes mediante contraste de fases a un aumento de 20x. El análisis de las imágenes fue realizado con el software NIS-Elements (Nikon, EEUU)

Caracterización por citometría de Flujo: En los pasajes 4 y 12 se realizó la caracterización celular mediante citometría de flujo, con los marcadores CD29, CD73, CD90, CD105 y CD166 como marcadores positivos y CD34 y CD45 como marcadores negativos (BD Biosciences, EEUU). Una vez alcanzada la confluencia celular del 80\% en los pasajes 4 y 12, las DPSCh fueron resuspendidas en buffer fosfato salino (PBS) 1x. La suspensión de DPSCh se incubó durante $30 \mathrm{~min}$ a temperatura ambiente y sin luz con los anticuerpos monoclonales IgG purificados (especificados anteriormente) marcados con isotiocianato de fluoresceína (FITC), ficoeritrina (PE) o complejo de clorofila-proteína peridinin con cianina-5.5 (PerCP-Cy5.5). Luego las células fueron lavadas con PBS 1x. Finalmente, las células se analizaron con un citómetro de flujo (FACSCalibur ${ }^{\mathrm{TM}}$, BD Biosciences, EEUU).

Caracterización por Inmunocitoquímica: A modo de doble control, al momento previo de realizar la citometría del pasaje 4, una alícuota de células fue sembrada sobre placas Millicell ${ }^{\odot}$ (Millicell EZ SLIDE, Millipore, EEUU) a una concentración de 3000 células por pozo. Las 
células fueron cultivadas por 7 días, alcanzando alta confluencia y las placas fueron fijadas en formaldehido $10 \%$. Para la caracterización inmunohistoquímica se utilizaron marcadores primarios CD90 y CD105 como positivos y CD34 y CD45 como negativos (Dako ${ }^{\oplus}$, Dinamarca). Brevemente; la peroxidasa endógena fue bloqueada utilizando peróxido de hidrógeno $0,9 \%$. Los anticuerpos primarios fueron incubados por 45 minutos y lavados con PBS. Luego las láminas fueron incubadas con anticuerpos anti-ratón/anti-conejo biotinilado y un complejo de estreptavidina/peroxidasa por 30 minutos cada uno (LSAB p-labeled streptavidin-biotin, Dako). Para visualizar la reacción un substrato de 3,30-diaminobenzidina-H20 fue utilizada (Dako ${ }^{\oplus}$, Dinamarca). Finalmente, las láminas fueron contra teñidas con una solución de Hematoxilina de Mayer. Como control negativo a la inmunocitoquímica, los anticuerpos primarios fueron sustituidos con PBS.

Como paso final, las células obtenidas fueron congeladas para futuras investigaciones. Se procedió al proceso de congelamiento lento, para ello, inicialmente se realizó la tripsinización de las botellas de cultivo, la suspensión celular fue colocada en tubos Falcon de $15 \mathrm{ml}$ y centrifugada a temperatura ambiente 400G (SORVALL ST-8R, Thermo Scientific, EEUU) durante 5 minutos, luego el sobrenadante fue descartado y el pellet fue resuspendido en $1 \mathrm{ml}$ medio clonogénico donde se procedió al conteo celular mediante placa de Neubahuer, luego se realizó la dilución con medio clonogénico hasta obtener una concentración celular de 1x106 cel/ $\mathrm{ml}$. La suspensión celular obtenida fue colocada en criotubos de $2 \mathrm{ml}$ (Greiner, Sigma Aldrich, Missouri, Estados Unidos), se cargó $1 \mathrm{ml}$ en cada criotubo y se adicionó un crioprotector (DMSO, Sigma Aldrich, Missouri, Estados Unidos) al 10\%. Rápidamente los criotubos fueron colocados en un dispositivo de enfriamiento controlado (Nalgene ${ }^{\varpi}$ Mr. Frosty, Sigma Aldrich, Missouri, Estados Unidos) que contiene alcohol isopropílico, directamente en un ul- tra freezer a $-80{ }^{\circ} \mathrm{C}$ (FORMA 89000, Thermo Scientific, EEUU) para su criopreservación.

Para futuros descongelamientos, se utilizará el método de descongelamiento rápido, donde los crioviales serán retirados del ultra freezer, y colocados directamente en un baño a $37^{\circ} \mathrm{C}$ hasta su pasaje a estado líquido. Inmediatamente se colocará la suspensión celular en un tubo Falcon con $10 \mathrm{ml}$ de medio de cultivo a modo de diluir el efecto del crioprotector. La nueva suspensión celular será centrifugada a 400G por 5 minutos, el sobrenadante se descartará y se re suspenderán las células en medio de cultivo clonogénico. Finalmente se colocarán en botellas de cultivo 25 para su expansión, registrando el número de pasaje.

Análisis estadístico: El análisis de viabilidad, morfología celular y la caracterización por inmunocitoquímica fueron valorados cualitativamente. Los resultados de citometría de flujo fueron analizados mediante ANOVA de dos vías considerando los factores: a) marcador utilizado, b) pasaje analizado (4 o 12). Los datos fueron sometidos previamente a test de normalidad, y todo el análisis se realizó con un nivel de significancia de $\alpha=0,05$. Para este análisis se utilizó el software SigmaStat V3.5.

\section{Resultados}

Durante el periodo de explante, las primeras células pudieron ser observadas migrando del mismo a la semana del inicio del cultivo, obteniendo una confluencia del $80 \%$ en el pocillo a los 15 días. Luego, en cada pasaje, la confluencia del $80 \%$ en cada botella se logró aproximadamente a los 7 días en todas las muestras.

Viabilidad y morfología celular: En todos los pasajes se observó una alta viabilidad celular. Las Figs. 2a y b muestran de forma representativa el estudio de fluorescencia. La morfología celular características de células madre mesenquimales de pulpa dental puede ser observada en las Figs. 2c y d. 
Fig. 2
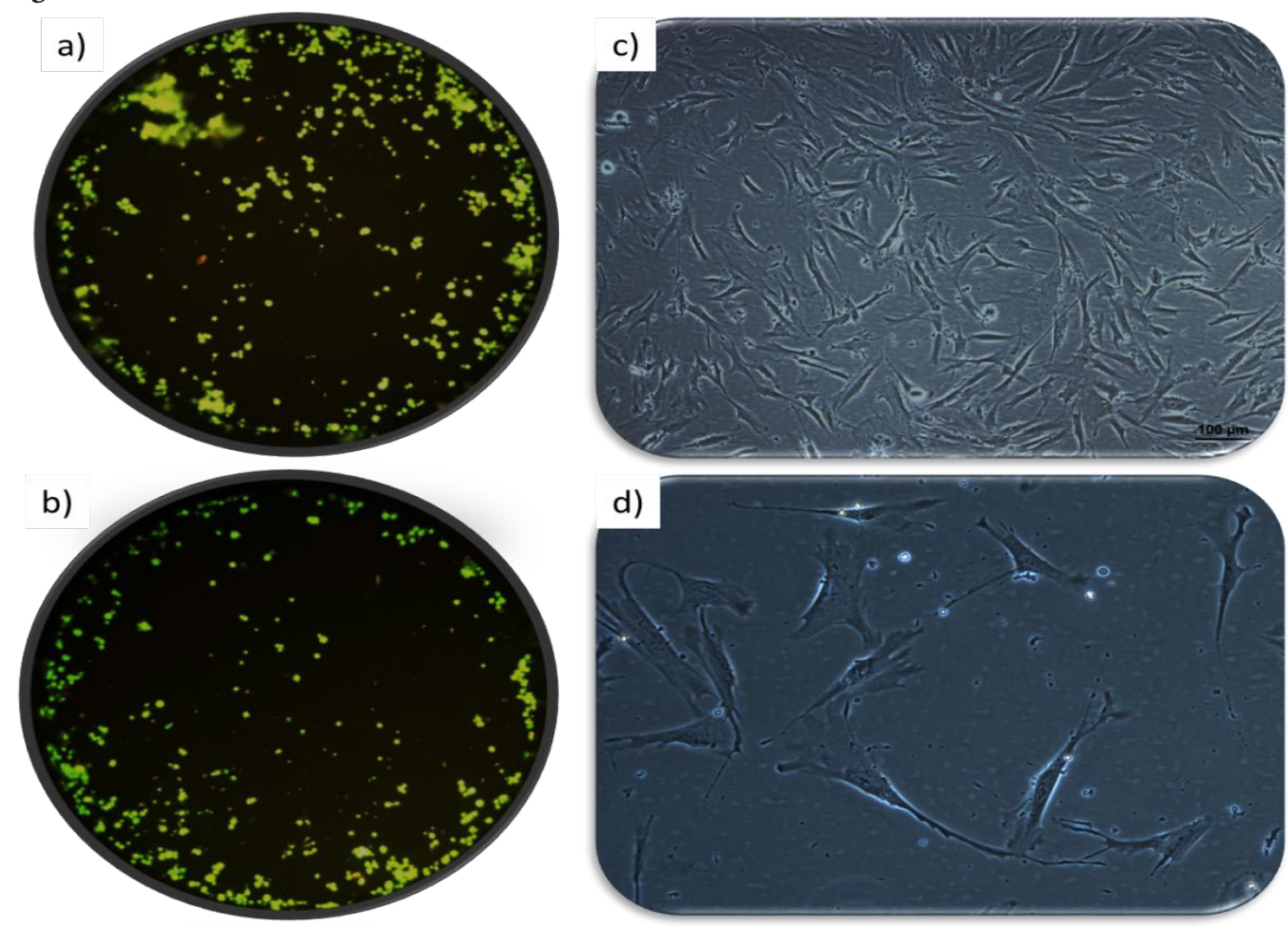

a y b) Imágenes representativas de los ensayos de viabilidad celular por fluorescencia (verde vivo / rojo muerto) aumento 40x. c y d) Microfotografías representativas de la morfología celular característica de las hDPSC aumento 200x y 400x respectivamente.

Citometría de flujo: los marcadores específicos estudiados CD29, CD73, CD90, CD105 y CD166 mostraron una elevada expresión, por encima del $84 \%$ en todos los casos tanto en el pasaje 4 como en el pasaje 12 . Los marcadores hematopoyéticos CD34 y CD45 mostraron una baja expresión, por debajo del 10\% en ambos pasajes. El análisis estadístico demostró que al estudiar el factor tiempo, más allá de que se observa una tendencia a la disminución en la expresión en los marcadores específicos, no se encontraron diferencias estadísticamente significativas en la expresión de marcadores entre pasaje 4 y 12 ( $\mathrm{p}<0,05)$. Por su parte, al comparar los marcadores específicos entre sí no se encuentran diferencias estadísticamente significativas entre pasaje 4 y 12. Lo mismo sucedió entre los marcadores hematopoyéticos. Los valores de expresión en los diferentes marcadores se encuentran representados en la Fig. 3. 
Fig. 3: Valores de expresión (\%) de los marcadores celulares de las DPSCh

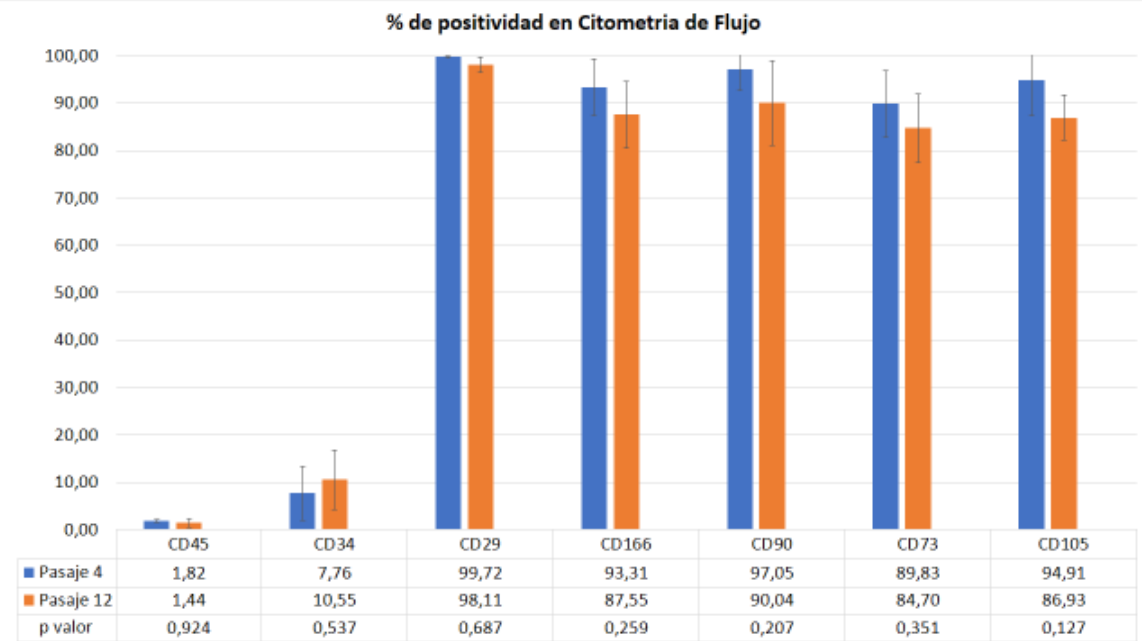

Se indica el p valor de la comparación en cada marcador correspondiente a pasaje 4 y 12.

Inmunocitoquímica: La inmunocitoquímica, confirmó el perfil fenotípico de las DPSCh, mostrando positividad para los marcadores CD90 y CD105, y mostrando ausencia de expresión para marcadores CD34 y CD45, corroborando los resultados encontrados en la citometría de flujo. La Fig. 4 muestra la expresión de los marcadores mediante inmunocitoquímica.

Fig. 4: Microfotografías representativas de los resultados obtenidos en la caracterización inmunocitoquímica de cada marcador.

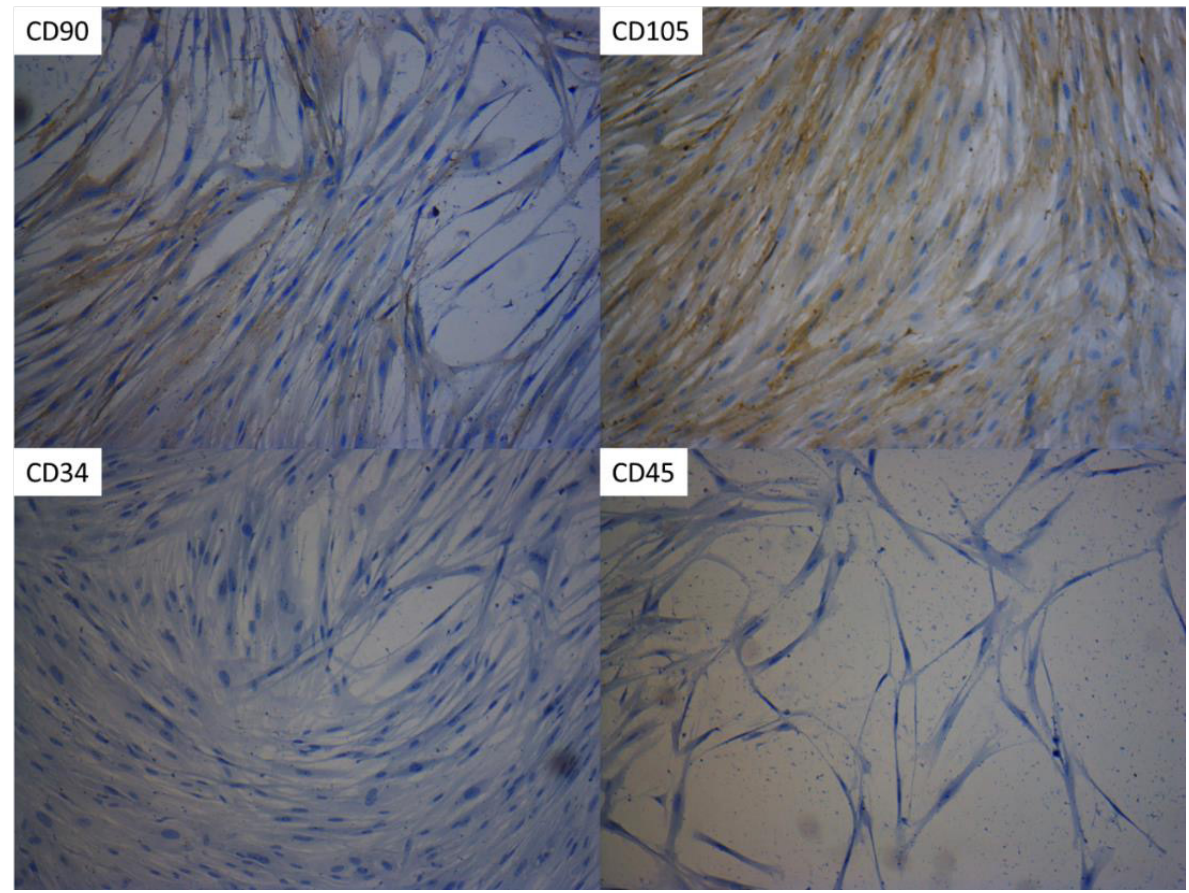

CD90 y CD105 muestran la pigmentación característica de la reacción de oxidación de la diaminobencidina, la ausencia de estos pigmentos en los marcadores CD34 y CD45 confirma la ausencia de expresión. Aumento 400x. 


\section{Discusión}

Este trabajo buscó el establecimiento de un protocolo simplificado de extracción, aislamiento primario y cultivo de Células Madre de Pulpa Dental Humana, a partir de terceros molares sanos cuya extracción estuviera indicada por motivos ortodóncicos. Según los resultados obtenidos, podemos rechazar la hipótesis nula, ya que fue posible obtener y caracterizar dichas células.

El aislamiento de células a partir de piezas dentarias sanas con indicación de extracción, que son consideradas normalmente como material biológico de descarte, terceros molares, primeros premolares y dientes supernumerarios generalmente extraídos por indicación ortodóncica ${ }^{(29)}$ resulta atractivo, ya que su obtención requiere de una técnica escasamente invasiva para el individuo (escasa morbilidad de la zona donante), sumado al potencial uso autólogo que confiere inmunocompatibilidad ${ }^{(21,30,31)}$.

El tercer molar es el último diente en desarrollarse; por lo cual en edades de entre 16 a 28 años se encuentra en una etapa temprana de desarrollo. Los estudios han demostrado que los terceros molares impactados extraídos no cariados son capaces de producir una cantidad óptima de tejido de pulpa dental para el aislamiento de DPSCh ${ }^{(31,32)}$. De este modo, en esta investigación se utilizaron terceros molares, ya que esta pieza es la última en culminar su desarrollo, lo que permite extraerla aún en etapas de desarrollo incompleto, lo que le otorga mayor capacidad de obtención de volumen de tejido pulpar, así como la probabilidad de encontrar células con mayor potencia ${ }^{(31,32)}$.

Se han podido aislar DPSC tanto de dientes sanos como de dientes con pulpa inflamada ${ }^{(33,34)}$. Según lo demostrado por Inostroza y col (25) las DPSC aisladas de la pulpa dental inflamada si bien mostraron características típicas de las Células Madres, presentan una capacidad inmunosupresora disminuida in vitro en comparación con las derivadas de la pulpa dental sana. Mientras que Chen y col (26) demostraron mayor potencial angiogénico en células provenientes de pulpas inflamadas.

El interés por aislar estas células se basa en que se ha demostrado que las DPSCh presentan mayor plasticidad y potencial proliferativo que las células del cordón umbilical, médula ósea y sangre periférica ${ }^{(21)}$. Las características particulares de las piezas dentarias, una cubierta mineralizada, proporciona un ambiente protegido de las influencias externas lo que le confiere a las DPSCh cualidades, a pesar de ser adultas, con algunas similitudes a las células embrionarias ${ }^{(21)}$. La principal ventaja respecto a las células madre embrionarias es que las DPSCh no generan controversias éticas en lo que respecta a su uso. Actualmente se presenta la posibilidad de inmortalizar esta línea celular lo que permitirá ampliar el campo de aplicación ${ }^{(16)}$.

La versatilidad de las DPSCh ha sido probada en diferentes estudios in vivo en modelos animales, dando resultados prometedores en el tratamiento de infarto de miocardio, regeneración de tejido nervioso, tratamiento de distrofia muscular, isquemia cerebral, regeneración de la córnea, así como capacidad angiogénica ${ }^{(10,16-22)}$. En la literatura se presentan básicamente dos métodos de obtención de DPSCh, el método de digestión enzimática (DE) de la pulpa dentaria y el método de explante (EX). El método DE permite obtener células rápidamente, en unas 24 horas, aunque requiere reactivos específicos (enzimas colagenasa y dispasa) y al liberar todas las células dentro del tejido pulpar, resulta en una población más heterogénea presentando además de DPSCh, fibroblastos e incluso pericitos ${ }^{(35,36)}$. Por otro lado, el método EX se basa en la migración celular en cultivo fuera del tejido, requiere de unos 5 a 15 días para observar dicha migración, resultando en un método más simple, económico y que brinda una población celular más homogénea ${ }^{(35,37,38)}$. Asimismo, al no requerir el uso de enzimas, lo hace más simple y económico para su potencial producción para uso clínico, ya que, si las requiriera, las enzimas certificadas para uso clínico son de alto costo. 
Por lo expuesto anteriormente, el método de explante fue el seleccionado para esta investigación. Un detalle metodológico por destacar es la realización de ranuras de retención en la placa de cultivos (Imagen 1e), lo cual facilita la adhesión del explante, ya que ante la falla de adhesión inicial del explante, las células no migrarán fuera de él y la muestra se pierde.

En este estudio se logró implementar una técnica de extracción de tejido pulpar que disminuye los riesgos de necrosis y contaminación gracias al trabajo a 4 manos, irrigación constante con solución estéril y exposición del tejido pulpar dentro de cámara de flujo con la ayuda de dos fórceps de extracción dentaria.

En cuanto a la morfología, como puede ser observado en la Imagen 2, las DPSCh presentan una morfología fibroblastoide característica, aunque tienden a mostrar más de 2 ramificaciones ${ }^{(37,39)}$. Por otro lado, estas imágenes permiten observar la homogeneidad celular, característica del método de explante.

El método de aislamiento propuesto fue efectivo para dientes almacenados hasta por $48 \mathrm{hs}$ a $4^{\circ} \mathrm{C}$ en medio de transporte, presentándose como un panorama alentador ya que permite una ventana de tiempo más amplia para su procesado, así como abre la posibilidad de la instauración de un biobanco. Esto concuerda con lo expuesto por Perry y col. ${ }^{(40)}$ donde se constató la posibilidad de obtener células viables incluso hasta dentro de las 120 horas.

En cuanto a la viabilidad celular, como se observa en la Imagen 2 se obtuvo una alta tasa de células vivas desde el pasaje 1 hasta el pasaje 12 inclusive. Estos datos corroboran la investigación de Martín-Piedra y col. ( ${ }^{(41)}$ los cuales observaron una alta viabilidad y tasa de proliferación en DPSCh hasta el pasaje 11. Considerando que llegar a pasaje 12 , implica un tiempo de cultivo prolongado, los autores consideran que constatar que esta línea celular no sufre alteraciones notorias hasta estos pasajes es muy relevante para futuras terapias regenerativas que se quieran desarrollar.
Estos resultados pueden ser corroborados en la literatura, donde diversos estudios han relatado que en pasajes elevados (hasta pasaje 15), las DPSCh mantienen su funcionalidad celular, viabilidad, tiempo de duplicación ${ }^{(35,39,41)}$, incluso asegurando su correcta criopreservación, sin alteraciones significativas sobre su proliferación celular o capacidad de diferenciación ${ }^{(42)}$. Sin embargo, aunque es conocido el efecto de pasajes elevados en la expresión de marcadores específicos en otras líneas celulares ${ }^{(43)}$, en DPSCh esta información es escasa y poco estudiada ${ }^{(44)}$. En los resultados presentados en este trabajo, la expresión de marcadores específicos y la negatividad de marcadores hematopoyéticos encontrada se condice con los datos encontrados en la literatura ${ }^{(23,37,45)}$. En este sentido, esta investigación brinda información relevante, confirmando que inclusive hasta el pasaje 12 las DPSCh expresan en la misma intensidad los marcadores específicos, sin aumentar significativamente la expresión de marcadores hematopoyéticos. Estos resultados, no solo confirman la exitosa obtención de DPSCh en nuestro país, sino que respaldan la metodología y procedimientos utilizados, al lograr mantener la homogeneidad y expresión de marcadores de potencialidad inclusive hasta el pasaje 12 .

Según se plantea por Dominici et al $2006^{(46)}$, los criterios para la caracterización de células madre mesenquimales son: Morfología de tipo fibrobalstoide, adherencia al plástico, expresión de marcadores de superficie CD73, CD90, CD105, CD11b, CD19, CD34, CD45, y HLA-DR, y diferenciación a linaje osteogénico, condrogénico y adipogénico. Una limitación de nuestro estudio fue la no inclusión de la evaluación de tri diferenciación, por lo que estos resultados deben ser interpretados con cautela. Futuros estudios que analicen la capacidad de diferenciación hacia diferentes linajes serán necesarios para demostrar la funcionalidad celular. De este modo, los resultados expuestos en este trabajo brindan respaldo científico para futuras 
investigaciones en miras a las terapias regenerativas mediante ingeniería de tejidos.

\section{Conclusiones}

Fue posible establecer con éxito un protocolo relativamente simple para la extracción, aislamiento primario y cultivo de DPSCh, logrando mantener la viabilidad, morfología celular y expresión de marcadores específicos de superficie celular incluso hasta el pasaje 12.

Si bien no se realizó la tri diferenciación para completar la caracterización de estas células, los hallazgos son alentadores y futuros estudios deberán comprobarse esta característica.

Posteriores estudios deberán realizarse enfocados en busca de la mejora de este procedimiento haciendo énfasis en la necesidad de generar protocolos más seguros, que eviten por completo el uso de productos xenogénicos y así permitir el uso de estas células de forma segura en terapias regenerativas e ingeniería de tejidos.

\section{Agradecimientos}

Los autores agradecen al Prof. Dr. Ronell Bologna y el Laboratorio de Patología Molecular de la Facultad de Odontología - Udelar por su colaboración en el análisis inmunocitoquímico, al Dr. Hugo Godiño por su colaboración en el trabajo de campo, a la Prof. Dra. Milka Bengochea por sus aportes y a todo el personal del INDT por su colaboración en la logística para la ejecución de esta investigación.

\section{Referencias}

1. Kim T-W, Che J-H, Yun J-W. Use of stem cells as alternative methods to animal experimentation in predictive toxicology. Regul Toxicol Pharmacol. 2019 Jul;105(January):15-29.

2. Daley GQ. Stem cells and the evolving notion of cellular identity. Philos Trans B. 2015 Oct 19;370(1680):20140376.

3. Shyh-Chang N, Ng H-H. The metabolic programming of stem cells. Genes Dev. 2017 Feb 15;31(4):336-46.

4. Kolios G, Moodley Y. Introduction to Stem Cells and Regenerative Medicine. Respiration. 2013;85(1):3-10.

5. Li N, Hua J. Interactions between mesenchymal stem cells and the immune system. Cell Mol Life Sci. 2017 Jul 18;74(13):2345-60.

6. Mortada I, Mortada R, Al Bazzal M. Dental Pulp Stem Cells and Neurogenesis. In: Advs Exp Medicine, Biology-Neuroscience and respiration. 2017. p. 63-75.

7. Keating A. Mesenchymal Stromal Cells: New Directions. Cell Stem Cell. 2012 Jun;10(6):709-16.

8. Caplan AI. Mesenchymal Stem Cells: Time to Change the Name! Stem Cells Transl Med. 2017 Jun;6(6):1445-51.

9. Peng L, Ye L, Zhou X. Mesenchymal Stem Cells and Tooth Engineering. Int J Oral Sci. 2009 Mar;1(1):6-12.

10. Ji ST, Kim H, Yun J, Chung JS, Kwon S-M. Promising Therapeutic Strategies for Mesenchymal Stem Cell-Based Cardiovascular Regeneration: From Cell Priming to Tissue Engineering. Stem Cells Int. 2017;2017:1-13.

11. Honda MJ, Watanabe E, Mikami Y, Saito Y, Toriumi T, Shirakawa T, et al. Mesenchymal Dental Stem Cells for Tissue Regeneration. Int J Oral Maxillofac Implants. 2013 Jan;28(6):e451-60.

12. Gronthos S, Mankani M, Brahim J, Robey PG, Shi S. Postnatal human dental pulp stem cells (DPSCs) in vitro and invivo. Proc Natl Acad Sci. 2000 Dec 5;97(25):13625-30.

13. Ulmer FL, Winkel A, Kohorst P, Stiesch M. Stem cells--prospects in dentistry. Rev Mens suisse d'odonto-stomatologie 2010;120(10):860-83. 
14. Sloan AJ, Waddington RJ. Dental pulp stem cells: what, where, how? Int J Paediatr Dent. 2009 Jan;19(1):61-70.

15. Honda MJ, Imaizumi M, Tsuchiya S, Morsczeck C. Dental follicle stem cells and tissue engineering. J Oral Sci. 2010 Dec;52(4):541-52.

16. Orimoto A, Kyakumoto S, Eitsuka T, Nakagawa K, Kiyono T, Fukuda T. Efficient immortalization of human dental pulp stem cells with expression of cell cycle regulators with the intact chromosomal condition. Papaccio G, editor. PLoS One. 2020 Mar 2;15(3):e0229996.

17. Luzuriaga J, Pastor-Alonso O, Encinas JM, Unda F, Ibarretxe G, Pineda JR. Human Dental Pulp Stem Cells Grown in Neurogenic Media Differentiate Into Endothelial Cells and Promote Neovasculogenesis in the Mouse Brain. Front Physiol. 2019 Mar 28;10(March):1-18.

18. Pai V, Vishwanath V, Prasanna J, Nadig R, Nadig R, Karthik J. Differentiation of isolated and characterized human dental pulp stem cells and stem cells from human exfoliated deciduous teeth: An in vitro study. J Conserv Dent. 2013;16(5):423.

19. Lan X, Sun Z, Chu C, Boltze J, Li S. Dental Pulp Stem Cells: An Attractive Alternative for Cell Therapy in Ischemic Stroke. Front Neurol. 2019 Aug 2;10(JUL):1-10.

20. Mead B, Logan A, Berry M, Leadbeater W, Scheven BA. Concise Review: Dental Pulp Stem Cells: A Novel Cell Therapy for Retinal and Central Nervous System Repair. Stem Cells. 2017 Jan;35(1):61-7.

21. Huang GT-J, Gronthos S, Shi S. Mesenchymal Stem Cells Derived from Dental Tissues vs . Those from Other Sources: Their Biology and Role in Regenerative Medicine. J Dent Res. 2009 Sep 18;88(9):792-806.

22. Longoni A, Utomo L, van Hooijdonk I, Bittermann G, Vetter V, Kruijt Spanjer E, et al. The chondrogenic differentiation potential of dental pulp stem cells. Eur Cells Mater. 2020 Feb 21;39:121-35.

23. Gronthos S, Brahim J, Li W, Fisher LW, Cherman N, Boyde A, et al. Stem Cell Properties of Human Dental Pulp Stem Cells. J Dent Res. 2002 Aug 13;81(8):531-5.

24. La Noce M, Paino F, Spina A, Naddeo P, Montella R, Desiderio V, et al. Dental pulp stem cells: State of the art and suggestions for a true translation of research into therapy. J Dent. 2014 Jul;42(7):761-8.

25. Inostroza C, Vega-Letter AM, Brizuela C, Castrillón L, Saint Jean N, Duran CM, et al. Mesenchymal Stem Cells Derived from Human Inflamed Dental Pulp Exhibit Impaired Immunomodulatory Capacity In Vitro. J Endod. 2020 Aug 1;46(8):1091-1098.e2.

26. Chen Y, Li X, Wu J, Lu W, Xu W, Wu B. Dental pulp stem cells from human teeth with deep caries displayed an enhanced angiogenesis potential in vitro. J Dent Sci. 2021 Jan 1;16(1):318-26.

27. Ferrúa CP, Centeno EGZ, Rosa LC da, Amaral CC do, Severo RF, Sarkis-Onofre R, et al. How has dental pulp stem cells isolation been conducted? A scoping review. Braz Oral Res. 2017 Dec 18;31:1-9.

28. Glickman GN. AAE Consensus Conference on Diagnostic Terminology: Background and Perspectives. J Endod. 2009 Dec;35(12):1619-20.

29. Yang X, Li L, Xiao L, Zhang D. Recycle the dental fairy's package: overview of dental pulp stem cells. Stem Cell Res Ther. 2018 Dec 13;9(1):347.

30. Scheller EL, Krebsbach PH, Konh DH. Tissue engineering: state of the art in oral rehabilitation. J Oral Rehabil. 2009 May;36(5):368-89.

31. Yalvac ME, Ramazanoglu M, Rizvanov AA, Sahin F, Bayrak OF, Salli U, et al. Isolation and characterization of stem cells derived from human third molar tooth germs of young adults: implications in neo-vascularization, osteo-, adipo- and neurogenesis. Pharmacogenomics J. 2010 Apr;10(2):105-13.

32. Atari M, Barajas M, Hernández-Alfaro F, Gil C, Fabregat M, Ferrés Padró E, et al. Isolation of pluripotent stem cells from human third molar dental pulp. Histol Histopathol. 2011;26(8):1057-70.

33. Pereira LO, Rubini MR, Silva JR, Oliveira DM, Silva ICR, Poças-Fonseca MJ, et al. Comparison of stem cell properties of cells isolated from normal and inflamed dental pulps. Int Endod J. 2012 Dec;45(12):1080-90.

34. Alongi DJ, Yamaza T, Song Y, Fouad AF, Romberg EE, Shi S, et al. Stem/progenitor cells from inflamed human dental pulp retain tissue regeneration potential. Regen Med. 2010 Jul;5(4):617-31. 
35. Karamzadeh R, Eslaminejad MB, Aflatoonian R. Isolation, Characterization and Comparative Differentiation of Human Dental Pulp Stem Cells Derived from Permanent Teeth by Using Two Different Methods. J Vis Exp. 2012 Nov 24;69(69).

36. Catón J, Bostanci N, Remboutsika E, De Bari C, Mitsiadis TA. Future dentistry: cell therapy meets tooth and periodontal repair and regeneration. J Cell Mol Med. 2011 May;15(5):1054-65.

37. Hilkens P, Gervois P, Fanton Y, Vanormelingen J, Martens W, Struys T, et al. Effect of isolation methodology on stem cell properties and multilineage differentiation potential of human dental pulp stem cells. Cell Tissue Res. 2013 Jul 29;353(1):65-78.

38. Raoof M, Yaghoobi MM, Derakhshani A, Kamal-Abadi AM, Ebrahimi B, Abbasnejad M, et al. A modified efficient method for dental pulp stem cell isolation. Dent Res J (Isfahan). 2014 Mar;11(2):24450.

39. Suchanek J, Soukup T, Visek B, Ivancakova R, Kucerova L, Mokry J. Dental pulp stem cells and their characterization. Biomed Pap. 2009 Mar 1;153(1):31-5.

40. Perry BC, Zhou D, Wu X, Yang F-C, Byers MA, Chu T-MG, et al. Collection, cryopreservation, and characterization of human dental pulp-derived mesenchymal stem cells for banking and clinical use. Tissue Eng Part C Methods. 2008 Jun;14(2):149-56.

41. Martin-Piedra MA, Garzon I, Oliveira AC, Alfonso-Rodriguez CA, Carriel V, Scionti G, et al. Cell viability and proliferation capability of long-term human dental pulp stem cell cultures. Cytotherapy. 2014 Feb;16(2):266-77.

42. Conde MCM, Chisini LA, Grazioli G, Francia A, Carvalho RV de, Alcázar JCB, et al. Does Cryopreservation Affect the Biological Properties of Stem Cells from Dental Tissues? A Systematic Review. Braz Dent J. 2016 Dec;27(6):633-40.

43. Wall ME, Bernacki SH, Loboa EG. Effects of Serial Passaging on the Adipogenic and Osteogenic Differentiation Potential of Adipose-Derived Human Mesenchymal Stem Cells. Tissue Eng. 2007 Jun;13(6):1291-8.

44. Ruparel NB, de Almeida JFA, Henry MA, Diogenes A. Characterization of a Stem Cell of Apical Papilla Cell Line: Effect of Passage on Cellular Phenotype. J Endod. 2013 Mar;39(3):357-63.

45. Vemuri MC, Chase LG, Rao MS. Mesenchymal Stem Cell Assays and Applications. In: Methods. Totowa, NJ: Humana Press; 2011. p. 3-8. (Methods in Molecular Biology; vol. 698).

46. Dominici M, Le Blanc K, Mueller I, Slaper-Cortenbach I, Marini F., Krause DS, et al. Minimal criteria for defining multipotent mesenchymal stromal cells. The International Society for Cellular Therapy position statement. Cytotherapy. 2006 Aug;8(4):315-7. 


\section{Comité de Ética:}

El presente trabajo fue aprobado por el Comité de Ética de la Facultad de Odontología Expediente número 091900-000143-13.

\section{Nota declaración de interés:}

Los autores declaran no poseer ningún conflicto de interés en la información científica brindada.

\section{Nota contribución de los autores:}

1. Concepción y diseño del estudio

2. Adquisición de datos

3. Análisis de datos

4. Discusión de los resultados

5. Redacción del manuscrito

6. Aprobación de la versión final del manuscrito

AF ha participado en: $1,2,3,4,5$ y 6 .

GG ha participado en: 1, 2, 3, 4, 5 y 6 .

LE ha participado en: 2, 3, 4, 5 y 6 .

AM ha participado en: 1,4 y 6 .

CT ha participado en 3, 4 y 6.

IA ha participado en: $1,3,4,5,6$.

\section{Nota de aceptación:}

Este artículo fue aprobado por la editora de la revista Mag. Dra. Vanesa Pereira-Prado. 